\section{Impossible Problems}

My convoluted academic history began by starting school at 10 years of age following a long illness. I was a busy student catching up through high school, while perhaps more interested in extracurricular activities.

At Massachusetts Institute of Technology (MIT), I first thought I wanted to pursue naval architecture, but one look at the implications of gigantic files of ship blueprints persuaded me to accept my parents' compromise of a Bachelor's degree in business and engineering administration. I was expected to follow the family focus in banking.

My bank jobs during high school prepared me to pass advanced standing exams in most business courses at MIT. As a result, I was able to follow my interests in science and engineering, and incidentally, my passion for racing on our championship sailing team. The science courses I took led me to a research job, not in banking, but in engineering of submerged arc welding at the Union Carbide Research Labs in Niagara Falls, NY.

This industrial job experience then motivated my transition to graduate school back at MIT. I finished my doctorate degree in less than 3 years with the highest course grades. I even had time to start a family and do some sailboat racing. My wife Page and I raced together and took turns at night looking after the baby and reading the instrument data on my continuous experiments. To the disappointment of my great professors, I went back to Union Carbide, where I became assistant director of research.

Eventually I lost interest in engineering administration and joined the faculty of Applied and Engineering Physics at Cornell University, which I had found to offer the most flexible opportunities in interdisciplinary sciences. Thus, I have been able to change scientific fields about six times in my career. During the past 30 years, I gradually completed the transition into biophysics.

Because I have lousy rote memory ability, I had avoided studying biological science. But I always liked "impossible" problems - like the many inaccessible molecular mechanisms at play in biological organisms. I try to solve biological problems by generating physical methods that often have to push fundamental physical limits. This has been fun and often productive.

My foray into biology was induced by Elliot Elson, a new colleague at Cornell, who presented an "impossible" problem. He is a great molecular biochemist, who was aiming then to determine how the newly discovered DNA double helix unwound to allow transcription. To approach the problem, we conceived fluorescence correlation spectroscopy in 1969 , as a tool to visualize the dynamics of the very sparse biomolecules that regulate biological processes

It was not until 1990 that Winfried Denk and I created multiphoton fluorescence microscopy, which has become a powerful and now ubiquitous tool for in vivo biophysical imaging. I consider it our greatest contribution to biology.

Once we became successful in developing tools for biology, I started to think, "What about medicine?" We are now trying to adapt multiphoton microscopy for application in clinical medicine for early diagnosis of disease and to support surgical intervention. Medicine is a special branch of engineering in my mind. The transition of a technology from the research laboratory to engineering applications is orders of magnitude more difficult than the research itself.

I changed fields many times, not to avoid trouble, but to move on to new challenges. Each time I entered a new field, I have built on what I learned from earlier experiences. For example, my research in the 1960s on continuous phase transitions or critical phenomena, then the hot topic in chemical physics, guided our understanding of phase separations in membrane structure and function, which we study today. It is fun to see this kind of connection evolve.

Despite my variable scientific focus, I have been relatively fortunate. Our first 99 papers submitted were accepted for publication. My first rejection came with the 100th manuscript, in which I had made an error in interpretation.

It takes patience, initiative, ingenuity, and perseverance to be successful in research. When students join my lab, I offer them two or three problems to choose from to get started, but they often pursue several different topics and engage in interdisciplinary collaborations. I think they must have freedom to learn to be innovators and thus to deal with the mistakes they make along the way. I try to offer my students opportunities to learn through challenges, and they have seldom failed.

My wife and I raised three sons, and that provided another teaching delight for me. When our twins were 10, we built a fullsize television set, which became our family TV for many years. And we always had our sailboats to maintain and to race as a competitive challenge. Now, when I look back, I cannot understand how my wife and I could hook up a sailboat behind our car on Friday afternoon, race all weekend-long, and go back to work on Monday morning.

As told to Laura Bonetta, a science writer based in Bethesda, MD. 